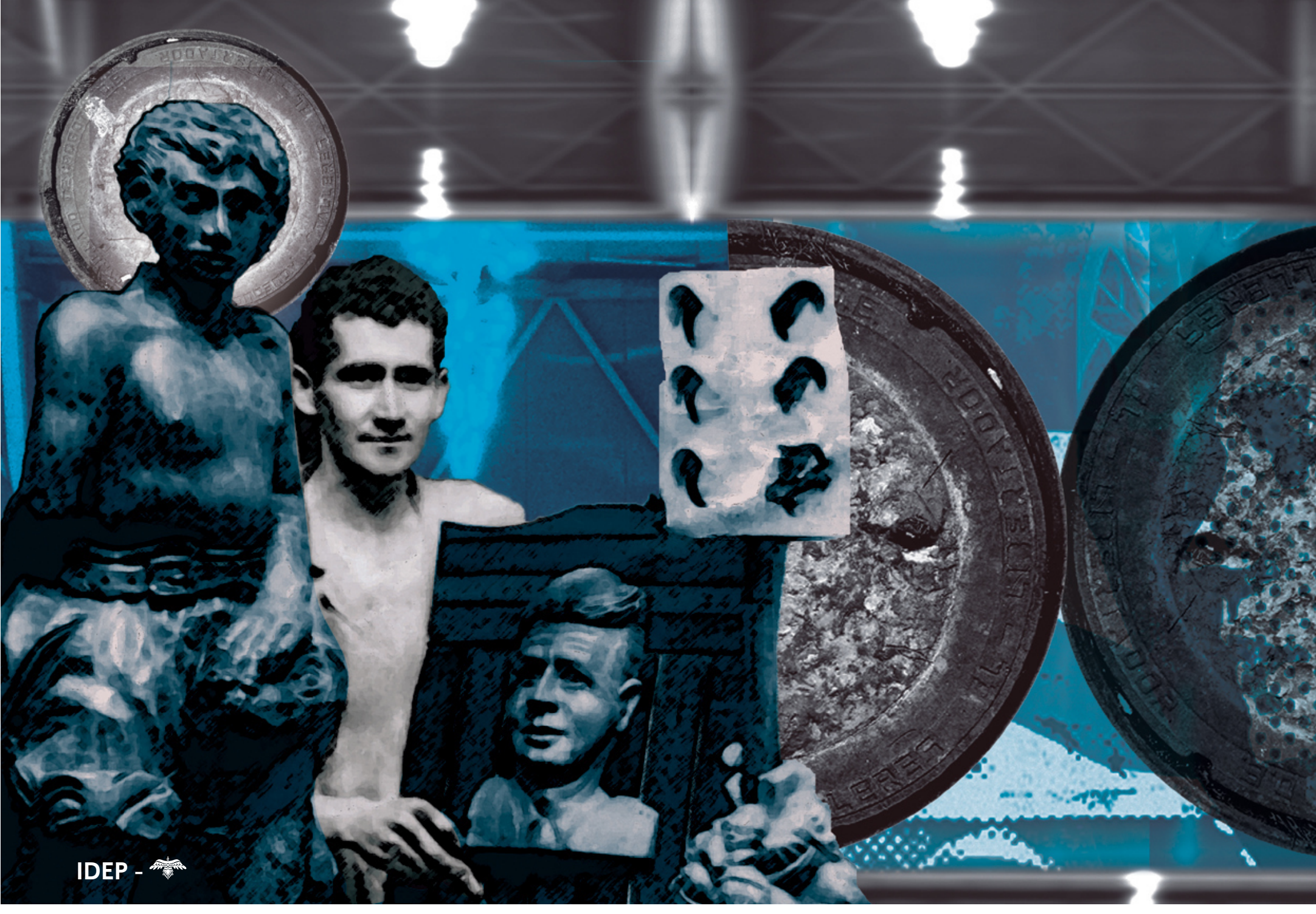

\title{
Desafíos y riesgos como promotores de buena enseñanza en profesores memorables
}

Challenges and risks as promoters of good teaching in memorable teachers Desafios e riscos como promotores de um bom ensino em professores memoráveis 


\section{Sebastián Adolfo Trueba ${ }^{1}$}

Doctor en Humanidades y Artes con mención en Ciencias de la Educación (UNR); Profesor de Educación Física (ISFD N84); Licenciado en Educación Física (UNL); Especialista en Docencia Universitaria (UNMdP); GIEEC (Grupo de Investigación en Educación y Estudios Culturales) dependiente del CIMED (Centro de Investigaciones Multidisciplinarias en Educación) de la Facultad de Humanidades - Universidad Nacional de Mar del Plata; correo electrónico: sebastiantrueba@gmail.com

\section{DOI: https://doi.org/10.36737/01230425.v2.n37.2019.2154}

Fecha de recepción: 22 de diciembre de 2018 / Fecha de aprobación: 30 de agosto de 2019

\begin{abstract}
Resumen
El presente artículo se desprende de una investigación biográfico-narrativa sobre la buena enseñanza de profesores memorables en la ciudad de Mar del Plata, Argentina. Se destacan aspectos sensibles de la formación de docentes, poco visibilizados pero muy potentes para la formación de maestras y maestros. Se puntualiza la importancia de asumir riesgos en una carrera desafiante, como es el caso de la docencia, a partir de las narrativas de los cuatro profesores memorables del estudio en cuestión. El registro de las buenas experiencias docentes, a partir de una construcción narrativa polifónica, puede constituirse en un aporte sustancial a la actual agenda de formación de docentes.

\section{Palabras clave:}

Desafíos educativos, riesgos en la enseñanza, buena enseñanza, profesores memorables, investigación biográfico-narrativa.
\end{abstract}

\section{Abstract}

The present article is derived from a biographical-narrative research on the good teaching of memorable teachers in the city of Mar del Plata, Argentina. It highlights sensitive aspects of teacher training, barely visible but very powerful for the training of teachers. It emphasizes the importance of taking risks in such a challenging career as teaching, based on the narratives of the four memorable teachers of the study in question. The registration of good teaching experiences based on a polyphonic narrative construction can constitute a substantial contribution to the current teacher training agenda.

\section{Keywords:}

challenges and risks in teaching; good teaching; memorable teachers; biographicalnarrative research.

\section{Resumo}

O presente artigo é derivado de uma pesquisa biográfica-narrativa sobre $o$ bom ensino de professores memoráveis na cidade de Mar del Plata, Argentina. Destaca aspectos sensíveis da formação de professores, pouco visíveis mas muito poderosos para a formação de professores. Enfatiza a importância de assumir riscos em uma carreira desafiadora, como o ensino, com base nas narrativas dos quatro professores memoráveis do estudo em questão. O registro de boas experiências de ensino com base na construção de uma narrativa polifônica pode constituir uma contribuição substancial para a atual agenda de formação de professores.

\section{Palavras-chave:}

Desafios e riscos no ensino; bom ensino; professores memoráveis; pesquisa biográficanarrativa. 


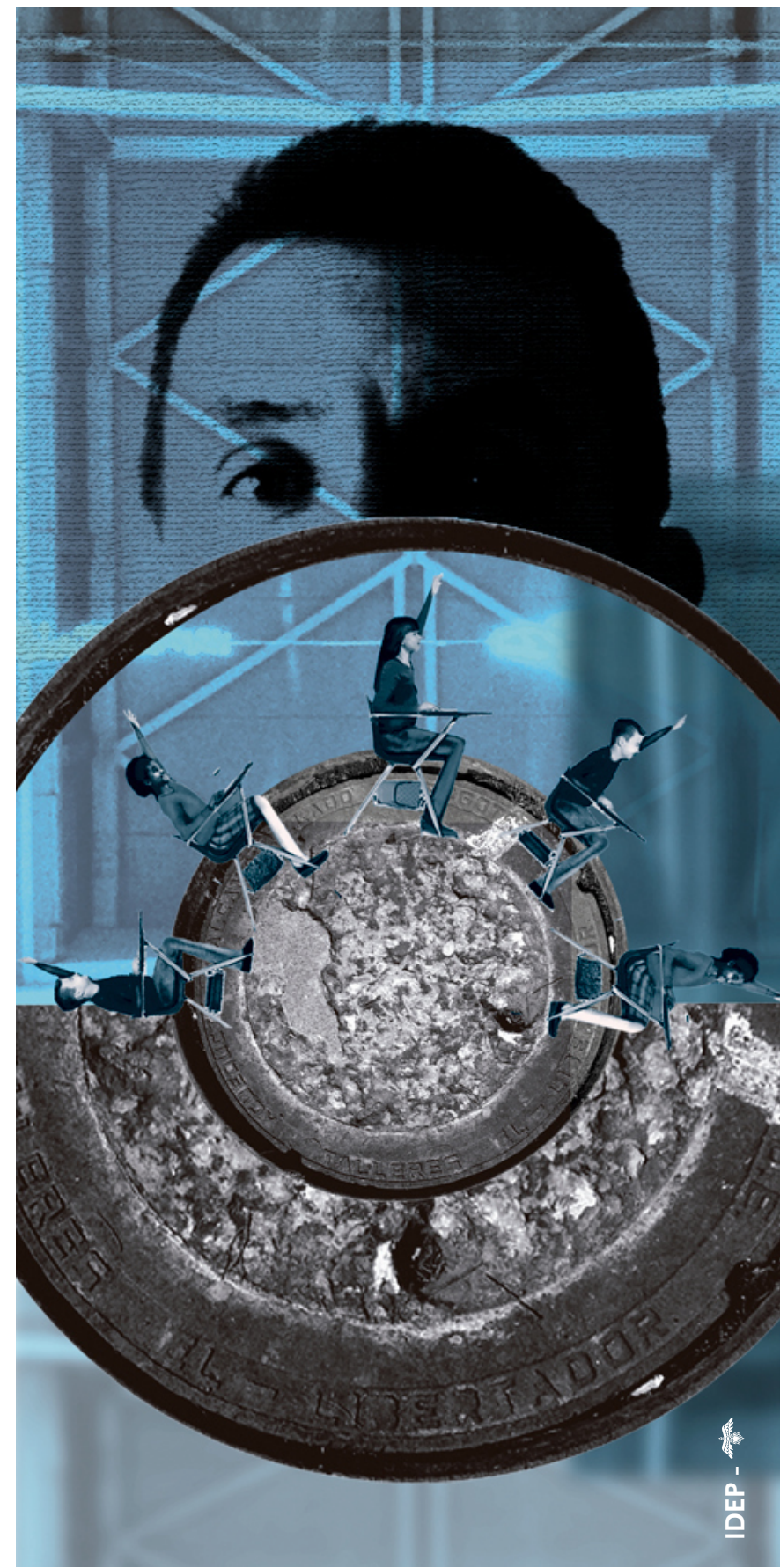

\section{Introducción}

- 1 presente artículo se desprende de la tesis doctoral del autor ${ }^{2}$

- y se inscribe en el marco de un proyecto de investigación, realizado entre 2018 y 2019, del Grupo de Investigación en Educación y Estudios Culturales (GIEEC) ${ }^{3}$. Aquí se presentan algunos avances que intentan constituir un aporte a lo que implica ser maestros y maestras actualmente.

La investigación se centró en recuperar las voces, ideas y sentimientos de los docentes seleccionados por sus colegas y ex alumnos como profesores memorables por su buena enseñanza (Álvarez y Porta, 2008; Bain, 2007 y 2010; Fenstermacher, 1989). Es decir, se recuperaron las experiencias de vida de estos docentes destacados para construir un registro que, si bien se reconoce como una perspectiva de la historia personal, se constituye, a su vez, en una historia colectiva (Branda, 2014).

En las siguientes páginas se desarrollarán tres secciones: La primera contextualizará la investigación; la segunda, desarrollará la categoría que aborda la influencia de los desafíos y riesgos en la buena enseñanza de los docentes memorables de este estudio y, la tercera, expondrá las conclusiones provisionales a las que se ha arribado.

\section{Contexto de la investigación}

"Profesores memorables para los docentes formadores de los profesorados de Educación Física de la ciudad de Mar del Plata", es una investigación cualitativa enmarcada en la perspectiva biográfico-narrativa (Bolívar, Domingo y Fernández, 2001; Bolívar, 2002; Porta, 2010), la cual se sustenta en la recuperación de los

2 "Profesores memorables para los docentes formadores de los profesorados de Educación Física de la ciudad de Mar del Plata", dirigida por la Doctora Alicia Caporossi y presentada en la Facultad de Humanidades y Artes de la Universidad Nacional de Rosario, Argentina.

3 EI GIEEC se encuentra bajo la órbita del Centro de Investigaciones Multidisciplinarias en Educación (CIMED) de la Facultad de Humanidades de la Universidad Nacional de Mar del Plata; el actual proyecto de investigación se titula: "Formación del Profesorado VIII. Narrativas y autobiografías otras. Políticas de formación, identidades docentes, prácticas memorables y pedagogías Queer".

Desafíos y Riesgos como Promotores de buena enseñanza en PRofesores memorables / Sebastián Adolfo Trueba 139 
estudios clásicos de la buena enseñanza (Fenstermacher, 1989), en los profesores memorables o extraordinarios (Bain, 2007) y en el marco de la Nueva Agenda de la Didáctica (Litwin, 1997) y de los estudios desarrollados por el GIEEC desde el 2003 (Álvarez y Porta, 2004; Álvarez, 2006; Álvarez y Porta, 2008; Flores y Porta, 2013; Porta, 2006; Porta y Martínez, 2015a y 2015b).

Ahora, en lo que respecta a la buena enseñanza, se parte de la idea de que ésta debe tener fuerza epistemológica y moral.

Preguntar qué es buena enseñanza en el sentido moral equivale a preguntar qué acciones docentes pueden justificarse basándose en principios morales y son capaces de provocar acciones de principio por parte de los estudiantes. Preguntar qué es buena enseñanza en el sentido epistemológico es preguntar si lo que se enseña es racionalmente justificable y, en última instancia, digno de que el estudiante lo conozca, lo crea y lo entienda (Fenstermacher, 1989, p. 158).

Esta idea se ve complementada por aportes de otros autores (Litwin, 1997; Fenstermacher y Richardson, 2005; Pruzzo, 2014 y Maggio, 2016), que permiten comprender la importancia y complejidad del asunto; por ejemplo, Souto define la buena enseñanza como:

Aquella que deja en el docente y en los alumnos un deseo de continuar enseñando y aprendiendo, a la vez que la incorporación y el dominio de nuevos conocimientos. Por la mala enseñanza, aquella que no produce los resultados esperados, que genera efectos no deseados, que aparenta o finge ser lo que no es, que desgasta sin producir, que frustra e inhibe nuevos aprendizajes y nuevas enseñanzas (1997, p. 117).

Mientras que Bain sintetiza la idea de buena enseñanza, presentada en este trabajo, de la siguiente manera.

No puedo hacer más hincapié en la simple pero magnífica noción de que la clave para comprender la mejor docencia no puede encontrarse en reglas o prácticas concretas, sino en las actitudes de los profesores, en su fe en la capacidad de logro de sus estudiantes, en su predisposición a tomar en serio a sus estudiantes y dejarlos que asuman el control sobre su propia educación, y en su compromiso en conseguir que todos los criterios y prácticas surjan de objetivos de aprendizaje básicos y del respeto y el acuerdo mutuo entre estudiantes y profesores (2007, p. 92).

Otro concepto fundamental para este trabajo es el de "Profesores memorables", una categoría presentada originalmente por Ken Bain, quien planteó que este tipo de docentes:
[...] conocen su materia extremadamente bien [...] son consumados eruditos, artistas o científicos en activo [...] están al día de los desarrollos intelectuales, científicos o artísticos de sus campos, razonan de forma valiosa y original en sus asignaturas, estudian con cuidado y en abundancia lo que otras personas hacen en sus disciplinas, leen a menudo muchas cosas de otros campos y ponen mucho interés en los asuntos generales de sus disciplinas: la historia, controversias y discusiones epistemológicas (2007, pp. 26-27).

Bain $(2007,2010)$ plantea la categoría de docente extraordinario o memorable incluyendo en ella a aquellos que se destacaban de diferentes maneras en la enseñanza.

Incluimos en nuestro estudio sólo a aquellos profesores que proporcionaron una fuerte evidencia de que ayudaban y animaban a sus estudiantes a aprender de manera que los hiciese merecedores de elogios y prestigio, tanto entre sus colegas directos de disciplina, como en la comunidad académica más amplia. También intentamos incluir algunos educadores que trabajan en los límites de las normas establecidas, definiendo la riqueza del aprendizaje de manera claramente novedosa. Así mismo, estudiamos a unas personas que tenían mucho éxito con algunas clases y bastante menos en otras [...]. Tales casos nos permitieron hacer algunas comparaciones entre lo que funciona y lo que no (Bain, 2007, p. 10).

El autor destaca como característica principal lo extraordinario, dejando en un segundo plano a lo memorable. Tal es así que a la hora de definirlo se inclina por la utilización del término extraordinario.

Para empezar este estudio tuvimos que definir lo que entendíamos por profesores extraordinarios [...]. Todos los docentes que elegimos [...] habían logrado un gran éxito a la hora de ayudar a sus estudiantes a aprender, consiguiendo influir positiva, sustancial y sostenidamente en sus formas de pensar, actuar y sentir. Lo que realmente hacían los profesores en el aula no nos importaba [...]. Elegimos a los profesores porque conseguían resultados educativos muy buenos (Bain, 2007, p. 15).

Sin embargo, preferimos alejarnos un poco de la implicancia que conlleva el docente extraordinario de Bain para destacar lo memorable, pensando a estos docentes como aquellos que "han influido positivamente en la identidad personal o profesional de sus estudiantes -que dejaron "marcas" (Porta y Yedaide, 2013, p. 42).

La investigación se desarrolló en tres etapas sucesivas: La primera, dedicada a hallar docentes memorables que participaron en el estudio, lo que implicó la aplicación de cuestionarios narrativos a profesores de educación física que trabajaban en las cuatro instituciones ofrecidas en la carrera Profesorado de Educación 
Física en la ciudad. Dicho instrumento constaba de tres consignas: Mencionar a docentes que se hubieran destacado en su formación del profesorado por su buena enseñanza; escribir frases breves que justifiquen su elección; y consignar cinco palabras que reflejaran la buena enseñanza de estos docentes seleccionados (Trueba, 2018).

Luego de hallados los docentes, se seleccionaron cuatro y se les entrevistó en profundidad; una vez transcritas las entrevistas, les fueron enviadas para que las corrigieran y ampliaran. Al ser devueltas por los memorables se pasó a la tercera etapa, que consistió en realizar un grupo focal con los cuatro protagonistas. Allí se profundizaron temas recurrentes en las entrevistas o que se destacaron por la potencia de sus conceptos, realizando puestas en común sobre cuestiones de interés para la investigación.

Con la transcripción de todos estos materiales se desarrolló el análisis conceptual, en donde se destaca, entre otras cosas, la importancia que tuvo en la formación de los memorables el asumir los riesgos y desafíos que la carrera (y la vida) les presentaba, lo que les constituyó en maestros que en la actualidad son destacados por sus colegas y ex-alumnos como extraordinarios. Es importante comprender que, a pesar de que este estudio se centró en los profesorados de educación física, sus enseñanzas son de interés para la formación docente de cualquier disciplina.

A continuación, se presentará dicho análisis por considerarlo de importancia para comprender mejor lo que implica ser un buen docente. Recuperar las experiencias y pensamientos de los mejores profesores puede constituirse en elemento clave para entender lo que implica ser maestras y maestros hoy.

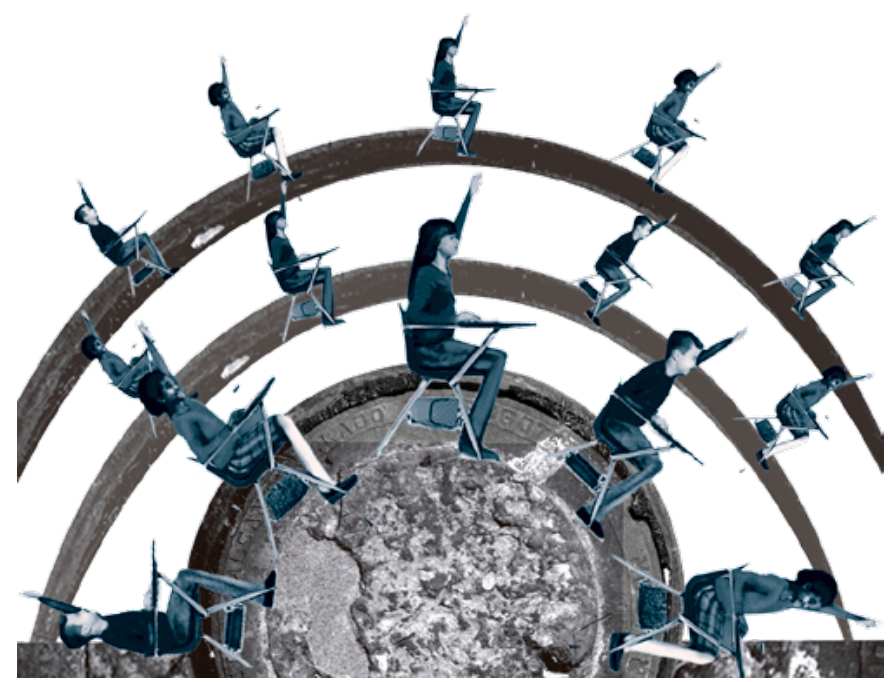

\section{Análisis ${ }^{4}$}

Un aspecto destacado por los docentes memorables es no se quedan en sus zonas de confort y asumen riesgos en sus carreras profesionales. Dichos desafíos y riesgos fueron enmarcados desde diferentes perspectivas por cada uno de los sujetos, mientras que la necesidad de ir más allá de lo que se esperaba de ellos y tener el coraje para afrontar desafíos, se constituyeron en pilares de su buena enseñanza.

El docente que conmueve es el que está comprometido y que por ello mismo entiende que sus alumnos aprenden en el marco del cuidado, corriendo riesgos moderados que son motores para el aprendizaje, pero que jamás los dejarían expuestos a una situación que cuya responsabilidad y control el propio docente no pudiera asumir (Maggio, 2016, p. 62).

Juan menciona en dos ocasiones el valor de poner en tela de juicio las creencias y los saberes del profesional de la enseñanza; en un primer momento lo hace refiriéndose a sí mismo y a la Maestría en Educación Corporal que cursó en la Universidad Nacional de La Plata.

[...] y ahora estoy desde hace rato con los últimos seminarios de una Maestría muy particular, como lo es, en la rama de la Educación Corporal, pero que yo creo..., tampoco quería estudiar algo que me siguiera reafirmando lo que yo ya pensaba; francamente, a los cincuenta años tenía ganas de que algo me haga más ruido que otra cosa. Porque a veces vamos desde el lugar cómodo; tengo que dejar de hacer capacitaciones en las que sigo escuchando cosas que ya sé. A veces sirve, porque no digo que están de más, pueden llegar a asentar una idea, pero quería hacer algo que se alejara un poco de mi lugar y la verdad que lo logro, evidentemente, me ha corrido de un lugar cómodo o de confort que ya tenía y que hoy me hace tener un discurso o poder ver muchas cosas, ideas o conceptos que manifiesto [...] Mi tesis, que voy a hacer en la Maestría, tiene que ver con esto, yo quiero saber si lo que yo les digo es tan efectivo como ellos creen que es, yo quiero poner en tela de juicio mi propio discurso (Entrevista, Juan, pp. 14 y 5).

También es importante destacar que son muy pocos los docentes que cursan licenciaturas en el campo de la Educación Física, y muchos menos quienes se involucran en una carrera de posgrado, algo que también dice mucho de los desafíos asumidos en su formación profesional. Juan plantea la intención de desafiarse

\footnotetext{
Los cuatro docentes memorables del estudio son identificados en este trabajo con los nombres: Carlos, Juan, Raúl y Simón. Durante la investigación, los cuatro sujetos dieron su consentimiento por escrito para que se los pueda mencionar en las publicaciones que se desprendieran de la tesis.
} 
a sí mismo con su tesis, debido a que no solo busca profundizar su formación, sino que lo hace a partir de repensar su propia enseñanza, es un desafío por continuar creciendo. Pero no es el único caso en el que se destaca esta situación.

- Carlos: Fuimos, yo te lo conté a vos (al entrevistador), fuimos a verlo a Domingo Blázquez Sánchez a Córdoba, a Jesús María, a la tarde a Blázquez Sánchez y, a la mañana, a Pierre Parlebas, un grupete de cinco o seis y, el día que llegamos a la inauguración, el viejo Dallo sentado ahí, ¿vos te acordás? (interrogando a Juan) ¡Alberto Dallo sentado ahí! Y te estoy hablando de hace diez años, no hace tanto, un tipo de un vuelo, que generó cosas que no sé si muy buenas, pero un ramal de los Giraldes, de los Mario López, de la "pirucha” Rossi, iy el tipo sentado ahí!

- Juan: Y con la grandeza que le desafíen lo que él sabe y sabiendo que le van a poner en jaque sus verdades (Grupo focal, pp. 19 y 20).

Lo que Juan destaca es ese desafío intelectual, el riesgo que asumió ese profesor al asistir al congreso como espectador siendo un profesor consagrado para la mayoría de asistentes. Ahora bien, asumir riesgos es otra de las cualidades destacadas por Juan y, no solo por él, sino por Carlos, quien lo menciona en su entrevista.

Juan me convoca al congreso anual que realiza el CADS porque Juan es vivísimo, lee lo que yo hago, les hago hacer un juego a los pibes, colegas ya, colegas; y lo último que dice es: "Carlos tomó riesgos", en el cierre dice: "Carlos tomó riesgos, con lo que él sabe le alcanzaba para hablar de las novedades" (Entrevista, Carlos, p. 18).

El riesgo y los desafíos ocupan un espacio importante en la enseñanza para Juan, sin embargo, para sus colegas esta categoría asume otros matices, como lo menciona Carlos en la cita anterior. De hecho, Carlos asumió riesgos en su misma cátedra de Metodología de la Investigación, cuando podría no hacerlo.

[...] vamos a ver a unos locos [alumnos] de Miramar $^{5}$ que tenían hipertensos haciendo trabajos de fuerza y yo estaba "recagado" hasta las patas, primero por el tema del riesgo..., y yo me agarraba el auto y me iba por el camino viejo a Miramar, y cuando ellos tomaban los datos yo estaba con ellos (Entrevista, Carlos, p. 19).

Carlos podría haberles hecho cambiar el tema de investigación a sus alumnos, sin embargo, asume el riesgo y los acompaña. También asumió riesgos y desafíos al dejar la seguridad y comodidad que tenía con sus cargos titulares en su localidad de origen. Hay

Miramar es una ciudad costera que dista 30 km de Mar del Plata. que tener en cuenta que ya era, entre otras cosas, el Director de Deportes de Rojas, y dejó todo para mudarse a Mar del Plata con su esposa, oriunda de esta ciudad.

Lidia viene en septiembre y busca laburo en la Villa Marista con Alvear, no sé si te lo han mencionado a Alvear padre, no Ricardito [...] Entonces dejé todo, con una licencia, el cargo en la municipalidad lo dejé con una licencia sin goce de sueldo [...] el 28 de febrero yo estaba con un pie acá y otro allá, no sabía qué hacer, el primero de marzo tenía que estar allá y fui con mi mujer porque teníamos que renunciar, fui a hablar con Alvear y me dijo: "Carlos, vaya a inspección de Educación Física, va a estar ahí la señora de Fernando Rodríguez Facal y va a haber otra inspectora que se llama Alicia Camilietti y dígales que va de parte mía y que usted quiere quedarse acá a vivir, quiere quedarse a trabajar". Te cuento esto porque es testimonial. Así que ese mismo día voy y me identifico "Carlos", me atiende Alicia Camilietti y me dice: "Hoy es martes, el viernes vaya a la escuela 16 que hay una asamblea de cobertura de cargos, avísele a su mujer"; "Bueno, gracias, le agradezco" [...] En la asamblea estábamos sentados en el [teatro] Payró..., ah no, no, era en la [Escuela No.] 16; sentados 25 profesores, no, menos, 15 éramos, el ruso Lerner..., todos profesores del plano de estas edades, 60, 65, 63 años. Sí, éramos 15, había 23 directoras porque había 23 cargos de 20 horas, 12 en la escuela y 8 a contraturno, extraescolares y Beatriz Artino, directora de la [Escuela No.] 62, la de Jara y 9 de julio, dice: "A mí me gusta el de barbita", a mi mujer la eligió otra y ese día me quedé. Ese día me quedé acá, me quedé con ese cargo y a los 3 días hicimos unos currículos..., impensado en esa época, año 80..., y digo: "Vamos a llevar a privada"; yo tenía buen currículum, nadie sabía dónde era Rojas, pero yo tenía buen currículum, tuve muy buenos profesores: Alberto Dallo, Mario López ¿te suenan estos? Giraldes [...] y el título nacional en ese momento tenía un peso, ahora no pasa nada, es todo lo mismo, pero en ese momento en la cabeza de los que decidían tenía peso, después vos podías ser un delincuente o una excelente persona. [...]. Entrego el currículum mío y el de mi mujer y, después, también los entregamos en el [colegio] San Roque y al otro día suena dos veces el teléfono, en una era el padre Héctor Compardón, sacerdote de Nuestra Señora del Huerto, que en esa época era Nuestra Señora del Camino, para decirme que vaya, que tiene 34 horas para darme y que a mi mujer no la quiere ni ver..., las vueltas de la vida..., y suena el teléfono (para el San Roque) y venimos acá y había 12 horas para Lidia y 4 para mí; todo tres días antes de que arrancaran las clases. [...] Un paquete armadito..., ojo, sin antigüedad, me lo dijo el cura, sin vacaciones de invierno y sin vacaciones de verano ¡Ojo! trabajé 14 años ahí, en la [Escuela No.] 62, trabajé 19 años, así que esa es un poco la historieta (Entrevista, Carlos, pp. 5 y 6).

Cambió la seguridad laboral de sus cargos por un proyecto familiar y la oportunidad de crecer profesionalmente porque, como él 
mismo afirmó, Rojas era un pueblo, mientras que en Mar del Plata, para ese momento, se había creado el Profesorado de Educación Física en el ISFD N¹9, había un CEF (Centro de Educación Física) muy importante, gran cantidad de escuelas públicas y privadas, y muchos clubes con actividades deportivas diversas. Tomar riesgos para comprometerse con sus proyectos de vida y profesionales lo impulsó a continuar creciendo y llegar a ser el referente que es en la actualidad.

Simón también vivió el desarraigo desde pequeño, al mudarse intempestivamente desde la localidad de Eduardo Castex, provincia de La Pampa, a Monte Grande en la provincia de Buenos Aires.

Resulta que gana el peronismo, se empieza a hacer difícil, los peronistas copan el club y yo te lo puedo decir..., nunca me lo dijo mi viejo, pero estaba sentenciado, se tenía que escapar. Nosotros teníamos dos chalets, dos coches, una posición importante y hubo que malvender todo a un médico del interior de La Pampa, y vino escapado a Buenos Aires. Regresa a Buenos Aires y no sabía a donde iba a ir y empezó a recorrer los pueblos del Gran Buenos Aires para ver dónde se instalaba y cayó en Avellaneda, en una inmobiliaria, y un señor, que estaba predestinado..., le cuenta que era médico y qué sé yo, y le dice: "Yo tengo el lugar para usted, sí o sí, usted tiene que comprar ahí e irse”, y ese lugar era Monte Grande, que es la cabecera del partido de Esteban Echeverría, que en aquel entonces también incluía a Ezeiza. Bueno, la cuestión es que le hizo comprar la casa, el casco de lo que había sido la famosa quinta del Dr. Montenegro. Era una de esas casas enormes con un pasadizo en el medio y las habitaciones a los costados, una de esas casas antiguas, gordas, grandes, con unas habitaciones enormes. El lote era de 20 por 60 y en plena calle Alem de Monte Grande, a una cuadra y media de la estación en la calle principal. Y estaba la posibilidad de comprar toda la esquina y estaban los dos lotes, que si hubiera comprado la esquina hubiera hecho un negocio bárbaro, pero como tenía miedo, no sabía lo que iba a pasar, por eso compró nada más que la casa. Yo tenía un circuito cuando me compran mi primera bicicleta, la famosa bicicleta Phillips negra, que era la única importada, inglesa. Me compraron la bicicleta y yo daba vueltas alrededor de la casa como un circuito, de lo enorme que era. Y ahí encontró su lugar (Entrevista, Simón, pp. 4 y 5).

Llama la atención que la narración comienza con la angustia de una persecución que los obliga a mal vender y huir de la ciudad en que vivían, y finaliza con la felicidad del niño que andaba en bicicleta en su nueva casa, entre la particular personalidad de su padre y las circunstancias de la vida que lo llevaron a ser una especie de nómade durante toda su juventud.

Al no haber colegio secundario en su localidad debía viajar a Banfield todos los días, lo mismo que al comenzar la Facultad de Medicina se trasladaba diariamente a Capital Federal, cuando debió realizar su residencia fue a Lanús, instaló su consultorio en Carlos Spegazzini y, al tomar sus cargos docentes, recorrió varias localidades del gran Buenos Aires como Guillón, Tristán Suárez, Llavallol, Ezeiza, Lobos, Roque Pérez y Saladillo, sin contar que todos los fines de semana recorría las canchas de fútbol de Banfield, Lanús, River Plate, Temperley y Los Andes, entre otros.

Simón adoptó la movilidad como una forma de avanzar continuamente hacia nuevos espacios, lo que le obligaba a continuar aprendiendo y, al hablar de movilidad, no solo hace referencia a los traslados geográficos constantes, sino a encarar nuevos desafíos formativos como dar clases en primer grado o, siendo estudiante de medicina, aceptar cargos en escuelas: rurales, técnicas y militares; $y$, en educación superior, en diferentes carreras, hecho que le obligó a actualizarse constantemente. Para Simón la enseñanza pasional implica preparación:

[...] donde voy me meto con pasión, ahora voy al [ISFD No.] 19 y me meto en las neurociencias con pasión, entonces me conecto y todo..., no podés hacerlo de taquito, yo lucho en casa con mi señora, y mis hijos y me dicen: “¿Por qué estudiás? Si vos lo sabes todo" ¡No! Yo me levanto de la mesa y les digo: Tengo que preparar la clase para mañana ¡Se enojan! Y dicen: “¿Qué vas a preparar? Si vos lo sabés todo" No, vos tenés que ir con una noción de lo que vas a dar, no podés improvisar y decir: "Che, ¿dónde quedamos?”; “¿en qué quedamos la clase anterior?” No, para mí no es eso (Entrevista, Simón, p. 20).

También relaciona la cuestión de movilidad con la diversidad en las vocaciones; al igual que su padre, Simón no disfruta quedándose en un solo tema de interés, por eso intentó e intenta explorar diferentes campos del saber.

Simón: Yo siempre les digo a los chicos: Hay muchas vocaciones, vos no podés ser una cosa sola. Yo tenía la medicina y la docencia y, bueno, y a mí me gusta la historia y me gusta de todo. Uno puede hacer muchísimas cosas, si vos le ponés lo de adentro... (Grupo Focal, p. 5).

El constante movimiento hacia nuevos desafíos construye una biografía llena de anécdotas. Simón desprecia a los médicos que solo hablan de medicina, porque él disfruta y se apasiona con una formación profesional que abarque diferentes saberes. A pesar de su doble carrera de docente y de médico siempre tuvo un gusto por el periodismo, la historia, por escribir, que no pudo cumplir $\mathrm{y}$, probablemente, ahí radiquen gran parte de sus inquietudes por temas diversos. 
Si yo le decía a mi viejo que lo que me gustó toda la vida, que tengo adentro, es el periodismo, la historia y ser escritor. Eso lo tengo adentro, por eso lo desarrollo, todas esas partes también las desarrollás. Es una parte oculta..., yo escribo canciones, los discursos por eso siempre me ponen acá..., bueno, siempre me gustó; pero sí, yo le decía al viejo: "Viejo, no... yo no quiero estudiar medicina”; o le agarraba un infarto y se moría ahí o me metía una patada en el traste y me echaba de casa. La obligación era esa, porque desde chiquito me disfrazaban de guardapolvo y todo eso..., y después venía, como yo le digo, la tía gorda, y dice: "Hay que lindo, el nene va a ser como el papá", y viene la abuela y te dice lo mismo... (Entrevista, Simón, p. 6).

Su historia familiar le llevó a recorrer diferentes carreras en Institutos de Formación Docente y en la Universidad, jubilándose de la medicina, pero continuando con la docencia.

Por su parte, se puede observar que Raúl también aceptó constantemente nuevos desafíos, los cuales hoy constituyen una parte importante de lo que se conoce como Educación Física en la ciudad de Mar del Plata; Raúl participó en la creación de reconocidas instituciones de la ciudad: colegios, institutos de formación docente y clubes. Así lo deja ver cuando indica: “Tuve la suerte de iniciar varias cosas, de estar en momentos importantes $\mathrm{y}$ en el inicio de varios emprendimientos, lo que me dio una perspectiva distinta” (Entrevista, Raúl, p. 8).

Así, Raúl reconoce el valor que ha tenido en su carrera el aceptar cada uno de los desafíos que afrontó, arriesgándose al fracaso y al descrédito, sin embargo, resalta mucho el reconocimiento que ha tenido, y tiene, entre sus colegas y exalumnos quienes, por otra parte, lo seleccionaron como profesor memorable. En la entrevista dejó entrever la emoción que le generaba dicho reconocimiento.

Yo estaba en frente a la casa de Tucumán, esperando para entrar a ver un espectáculo de luces y sonidos que se hace ahí, y había allí 7 u 8 "muchachos" (de cuarenta y cincuenta [años]) que también estaban esperando para entrar y me miraban. Uno de los colegas que estaba conmigo me dice: "Che, Raúl, me parece que esos muchachos te miran, como que te conocen"; y se arrimó uno y me dice: "Raúl, yo soy fulano de tal”, “¿cómo te va?”; después se arrimaron otros y habían sido casi todos alumnos míos en el secundario, eso es una gratificación extraordinaria que alguien venga, te salude, o sea, el hecho del saludo implica un afecto, si no: "A este ni lo saludo"; eso lo recibo muchas veces y es una gratificación (Entrevista, Raúl, p. 10).

\section{Conclusiones provisorias}

Cada uno aceptó los riesgos y desafíos que la vida y la profesión les presentó, convirtiéndose esto en una forma de crecimiento humano y profesional. Todos vivieron desafíos diferentes y todos los capitalizaron en una mejora en la calidad de su enseñanza, resaltándolo en su narraciones autobiográficas, destacándolo por sobre otros tópicos.

El riesgo de aventurarse a lo desconocido, alejarse de las zonas de confort y comprometerse con los desafíos de la vida profesional, es otra forma de ir más allá de lo estrictamente necesario para continuar creciendo como persona y como docente. Este viaje "odiseico" (Porta y Martínez, 2015a y 2015b) los termina posicionando como referentes en la formación de profesores de educación física en Mar del Plata. Lo que no puede determinarse es hasta qué punto funciona este motor que los construye como docentes memorables, porque, o ellos aceptan los desafíos que la vida les propone, o son ellos quienes toman riesgos para que su vida sea desafiante.

Hoy constituirse en docente implica verse atravesado por las narrativas de profesores y profesoras formadores que se destacan por la pasión y el coraje para afrontar la carrera de manera desafiante. Interpretar que estos aspectos, más vinculados a la sensibilidad, y menos a cuestiones técnicas, marcaron la vida de los mejores formadores de docentes, permite comprender el peso que estos temas, invisibilizados por años, tienen en la constitución de las y los maestros que se puedan destacar por su buena enseñanza. Este artículo intenta dejar en evidencia la importancia de estos temas, para que ocupen un lugar de mayor trascendencia en la agenda de la formación de maestros y maestras. 


\section{Referencias}

Álvarez, Z. (2006). El discurso como unidad didáctica. En Porta, L., y Sarasa, M. C. (Eds.), Miradas críticas en torno a la formación docente y condiciones de trabajo del profesorado (pp. 245-266). Mar del Plata: GIEEC, Facultad de Humanidades, Universidad Nacional de Mar del Plata.

Álvarez, Z., y Porta, L. (2004). La formación del profesorado. Abordajes teóricos y miradas prácticas. Mar del Plata: GICIS, Facultad de Humanidades, Universidad Nacional de Mar del Plata.

Álvarez, Z., y Porta, L. (2008). Biografías memorables: relatos sobre buenos profesores. En Porta, L., y Sarasa, M. C. (Eds.), Formación y desarrollo de la profesión docente en el profesorado: Las buenas prácticas y sus narrativas (pp. 219-245). Mar del Plata: GIEEC, Facultad de Humanidades, Universidad Nacional de Mar del Plata.

Bain, K. (2007). Lo que hacen los mejores profesores de universidad. Valencia: Universidad de Valencia.

Bain, K. (2010). Qué es la buena enseñanza. Revista de Educación, Año 3, No. 4, pp. 63-74. Mar del Plata. EUDEM.

Bolívar, A. (2002). ¿De nobis ipsis silemus?: Epistemología de la investigación biográfico-narrativa en educación. Revista Electrónica de Investigación Educativa, 4(1). Obtenido el 22 de abril de 2015 desde http://www.redie.uabc.mx/vol4no1/contendido-contenido.html

Bolívar, A., Domingo, J., y Fernández, M. (2001). La investigación biográfico-narrativa en educación. Enfoque y metodología. Madrid: La Muralla.

Branda, S. (2014). La investigación biográfico-narrativa en Educación. Revista de Educación, Año 4, No. 7, pp. 243-256. Mar del Plata: EUDEM.

Fenstermacher, G. (1989). Tres aspectos de la filosofía de la investigación sobre la enseñanza. En Wittrock, M. La investigación en la enseñanza I. Enfoques, teorías y métodos. Barcelona: Paidós.

Fenstermacher, G., y Richardson, V. (2005). On making determinations of quality in teaching. Teachers' College Record, 107(1), pp. 186-213. DOI: https://doi.org/10.1111/j.1467-9620.2005.00462.x

Flores, G., y Porta, L. (2013). Urdimbre ética en la enseñanza universitaria desde la perspectiva de los estudiantes: conjunción de intelecto y afecto en los profesores memorables. Redex. Revista de Educación de Extremadura, No. 5, pp.29-49.

Litwin, E. (1997). El campo de la didáctica: la búsqueda de una nueva agenda. En Camilloni, A. Corrientes didácticas contemporáneas. Buenos Aires: Paidós.

Maggio, M. (2016). Enriquecer la enseñanza. Los ambientes con alta disposición tecnológica como oportunidad. Buenos Aires: Paidós.

Porta, L. (2006). La buena enseñanza en el aula universitaria a partir de las narrativas de los docentes. Miradas críticas en torno a la formación docente y condiciones de trabajo del profesorado (pp. 215-243). Mar del Plata: GIEEC.

Porta, L. (2010). La investigación biográfico narrativa en educación. Entrevista a Antonio Bolívar. Revista de educación, No. 1, Año 1, pp. 201-212. Mar del Plata. EUDEM. 
Porta, L., y Martínez, C. (2015a). Pasiones: Roberto Kuri. Mar del Plata: EUDEM.

Porta, L., y Martínez, C. (2015b). Pasiones: Cristina Piña. Mar del Plata: EUDEM.

Porta, L., y Yedaide, M. M. (2013). La pasión educa: Enunciaciones apasionadas de profesores memorables universitarios. RAES, Revista Argentina de Educación Superior, Año 5, No. 6, pp. 35-50.

Pruzzo, V. (2014). La enseñanza irrelevante y lagunas de aprendizaje. Didáctica General. Investigación empírica y discusiones teóricas. Amax Ediciones.

Souto, M. (1997). La clase escolar. Una mirada desde la didáctica de lo grupal. En Camilloni, A. Corrientes didácticas contemporáneas. Buenos Aires: Paidós.

Trueba, S. (2018). Características de los mejores docentes de los profesorados de educación física. Revista Praxis, Vol. 14(1), Obtenido el 20 de Diciembre de 2018 desde http://revistas.unimagdalena.edu.co/ index.php/praxis/article/view/2540 DOI: https://doi.org/10.21676/23897856.2540 